\title{
Angiotensin-(1-7) improves oxygenation, while reducing cellular infiltrate and fibrosis in experimental Acute Respiratory Distress Syndrome
}

Vanessa Zambelli ${ }^{1}$, Giacomo Bellani ${ }^{1,2^{*}}$, Roberto Borsa ${ }^{1}$, Federico Pozzi ${ }^{1}$, Alice Grassi ${ }^{1}$, Margherita Scanziani ${ }^{1}$, Vittoria Castiglioni ${ }^{3}$, Serge Masson ${ }^{4}$, Alessandra Decio ${ }^{5}$, John G Laffey ${ }^{6,7}$, Roberto Latini ${ }^{4}$ and Antonio Pesenti ${ }^{1,2}$

\author{
* Correspondence: \\ giacomo.bellani1@unimib.it \\ ${ }^{1}$ Department of Health Sciences, \\ University of Milano-Bicocca, Monza, \\ Italy \\ ²Department of Emergency, San \\ Gerardo Hospital, Monza, Italy \\ Full list of author information is \\ available at the end of the article
}

\begin{abstract}
Background: The renin-angiotensin system (RAS) plays a role in the pathogenesis of ARDS, Angiotensin II (Ang-II) contributing to the pathogenesis of inflammation and fibrogenesis. Angiotensin-(1-7) (Ang-(1-7)) may antagonize the effects of Ang-II. This study was aimed at evaluating the potential for Ang-(1-7) to reduce injury, inflammation and fibrosis in an experimental model of ARDS in the acute and late phases.

Methods: Male Sprague Dawley rats underwent an instillation of $0.1 \mathrm{M}$ hydrochloric acid $(\mathrm{HCl}, 2.5 \mathrm{ml} / \mathrm{kg})$ into the right bronchus. In an acute ARDS study, acid-injured rats were subjected to high stretch mechanical ventilation $(18 \mathrm{ml} / \mathrm{kg})$ for $5 \mathrm{~h}$ and randomized to receive an intravenous infusion of either vehicle (saline), Ang-(1-7) at low dose $(0.27 \mu \mathrm{g} / \mathrm{kg} / \mathrm{h})$ (ALD), or high dose $(60 \mu \mathrm{g} / \mathrm{kg} / \mathrm{h}$ ) (AHD) starting simultaneously with injury or $2 \mathrm{~h}$ afterwards. Arterial blood gas analysis and bronchoalveolar lavage (BAL) were performed to assess the injury. For the late ARDS study, after $\mathrm{HCl}$ instillation rats were randomized to either vehicle or high dose Ang-(1-7) (300 $\mu \mathrm{g} / \mathrm{kg} /$ day) infused by mini osmotic pumps for two weeks, and lung hydroxyproline content measured.

Results: In the acute ARDS study, Ang-(1-7) led to a significant improvement in oxygenation $\left(\mathrm{PaO}_{2} / \mathrm{FiO}_{2}\right.$ : vehicle $359 \pm$ 86; ALD $436 \pm 72 ; \mathrm{AHD} 44442 \pm 56$; ANOVA $p=0.007$ ) and reduced white blood cells counts (vehicle 4,519 $\pm 2,234 ; A L D$ $2,496 \pm 621 ;$ AHD 2,744 $\pm 119 / \mathrm{mm}^{3}$; ANOVA $\left.p=0.004\right)$. Only treatment with high dose Ang-(1-7) reduced inflammatory cell numbers in BAL (vehicle $127 \pm 34$; AHD $96 \pm 34 / \mu l ; p=0.033)$. Interestingly also delayed administration of Ang-(1-7) was effective in reducing injury. In later ARDS, Ang-(1-7) decreased hydroxyproline content (649 \pm 202 and 1,117 $\pm 297 \mu \mathrm{g} / \mathrm{lung} ; p<0.05)$.
\end{abstract}

Conclusions: Angiotensin-(1-7), decreased the severity of acute lung injury and inflammation induced by combined acid aspiration and high stretch ventilation. Furthermore, continuous infusion of Ang-(1-7) reduced lung fibrosis 2 weeks following acid aspiration injury. These results call for further research on Ang-(1-7) as possible therapy for ARDS.

Keywords: ARDS; Renin-angiotensin system; Angiotensin-(1-7)

\section{Springer}

(c) 2015 Zambelli et al.; licensee Springer. This is an Open Access article distributed under the terms of the Creative Commons Attribution License (http://creativecommons.org/licenses/by/4.0), which permits unrestricted use, distribution, and reproduction in any medium, provided the original work is properly credited. 


\section{Background}

To date, no therapies are available to modify the clinical course and improve the outcome of Acute Respiratory Distress Syndrome (ARDS) [1]. The only supportive strategies are mechanical ventilation and conservative management of intravenous fluids, but prolonged ventilation could exacerbate a pre-existing lung injury and lead to ventilator-induced lung injury (VILI) [2].

The pathogenesis of ARDS can be influenced by the activation of the reninangiotensin system (RAS), a well-known hormonal system involved in the regulation of blood pressure homeostasis and fluid and salt balance. The main effector of this system is angiotensin II (Ang-II), which derives from the proteolytic cleavage of angiotensin I (Ang-I) by angiotensin converting enzyme (ACE). Ang-II, in addition to its hemodynamic functions, is involved in inflammatory and fibrogenic processes [3-5]. Indeed the activation of Ang-II and its receptor angiotensin II receptor type $1\left(\mathrm{AT}_{1} \mathrm{R}\right)$ plays a role in the pathophysiology of several diseases, including atherosclerosis, myocardial infarction, stroke, diabetes, nephrosclerosis, and tumorigenesis [5]. An association has been demonstrated between ACE polymorphism and the susceptibility, progression and outcome in ARDS [6-9].

In parallel with $\mathrm{ACE} / \mathrm{Ang}-\mathrm{II} / \mathrm{AT}_{1} \mathrm{R}$ axis, renin-angiotensin system has a counterregulatory axis, which is composed by angiotensin-(1-7) (Ang-(1-7)), its receptor Mas, and the main rate limiting step ACE2 [10]. Ang-(1-7) is a biologically active heptapeptide released from the cleavage of Ang-II by ACE homolog ACE2 or from Ang-I by other peptidases [11-13]. It exerts its action via the Mas receptor, which is a non- $\mathrm{AT}_{1} / \mathrm{AT}_{2} \mathrm{G}$ protein-coupled receptor. Ang-(1-7) mediates some ACE inhibitor-related effects: it opposes Ang-II actions, especially vasoconstriction [14], proliferation [15], and inflammation [16]. In a model of antigen-induced arthritis [17], Ang-(1-7) modulated rolling and adhesion of leukocytes to endothelium with improvement of joint hypernociception. Ang-(1-7) can inhibit leukocyte pro-inflammatory functions by activating Mas receptor on their surface [5]. In the context of ARDS, Imai et al. showed the crucial involvement of ACE2 in the pathogenesis of ARDS in three different experimental models [18]. In particular, ACE2 knockout mice showed greater lung elastance than control mice, worst oxygenation, and increased inflammation in experimental models of acute lung injury induced by acid aspiration or endotoxin (LPS) or caecal ligation and puncture (CLP) [18]. Moreover the administration of recombinant human ACE2 in wild-type mice attenuated acute lung injury, demonstrating the protective effects of ACE2 [18]. Other studies demonstrated that Ang-(1-7) acts also on lung remodeling and fibrosis development, Ang-(1-7) can enhance the apoptosis of fibrocytes, and reduces the expression of transforming growth factor $\beta$ (TGF- $\beta$ ) and collagen deposition [16,19-22]. In a bleomycin-induced lung fibrosis model, the intratracheal administration of Ang-(1-7) through lentivirus led to a significant reduction in pulmonary fibrosis [23]. The potential for Ang-(1-7) to attenuate ARDS severity and lung fibrosis in preclinical ARDS models is not known.

Even if the beneficial effects of Ang-(1-7) in different models of ARDS have already been shown [24], we aimed to further exploit the therapeutic potential of Ang-(1-7) for ARDS, also administrating it with a delayed timing in the acute phase and for a prolonged period of 2 weeks to evaluate the impact of fibrosis. To the best of our knowledge, these aspects have not been addressed in previous studies. We hypothesized that, in early ARDS, Ang-(1-7) would reduce the severity of lung injury induced following 
the combined 'insults' of pulmonary acid aspiration followed by high stretch mechanical ventilation.

Prolonged ARDS requiring ongoing mechanical ventilation can induce lung fibrosis, which is a significant contributor to poor outcome in ARDS [25]. Given this, we further wished to determine the potential for Ang-(1-7) to attenuate the development of fibrosis in an experimental model of late ARDS induced by unilateral acid instillation [26]. We hypothesized that continuous Ang-(1-7) treatment could reduce the collagen deposition and improve long-term outcome.

\section{Methods}

\section{Animals}

Male Sprague Dawley rats (200 to $250 \mathrm{~g}$ ) were obtained from Harlan Laboratories (Udine, Italy) and maintained under standard laboratory condition in Bicocca University in Monza (Italy). Procedures involving animals and their care were conducted in conformity with the institutional guidelines complying with national (D.L. n. 116, G.U., suppl. 40, 18 Febbraio 1992, Circolare n. 8, G.U., 14 Luglio 1994) and international laws and policies (EEC Council Directive 86/609, OJ L 358, 1, 12 December 1987; US National Research Council's Guide for the Care and Use of Laboratory Animals, 2011). The study was approved by the ethical committee of our institution.

\section{Acute ARDS study: two-hit model}

Animals were anesthetized with Ketamine $100 \mathrm{mg} / \mathrm{kg}$ and Xylazine $4 \mathrm{mg} / \mathrm{kg}$ (Ketavet 100, Intervet Productions, Aprilia, Latina, Italy; Rompun 2\%, Bayer, Milano, Italy), orotracheally intubated and subjected to high stretch ventilation (Inspira ASV, Harvard Apparatus, Holliston, MA, USA) with the following parameters: tidal volume $18 \mathrm{ml} / \mathrm{kg}$; respiratory rate 35/min; PEEP 2 to $2.5 \mathrm{cmH}_{2} \mathrm{O}$; inspiration to expiration ratio (I/E) 35\%; fraction of inspired oxygen $\left(\mathrm{FiO}_{2}\right)$ 0.5. At the beginning, after $3 \mathrm{~h}$ of treatment and at the end of the 5-h experiment, a recruitment maneuver (to $30 \mathrm{cmH}_{2} \mathrm{O}$ for $10 \mathrm{~s}$ ) was performed. Injury was induced by instillation of $0.1 \mathrm{M}$ hydrochloric acid $(\mathrm{HCl})$ $(2.5 \mathrm{ml} / \mathrm{kg})$ into the right bronchus through a PE10 catheter. Acid-induced damage in the right lung was confirmed by micro-computed tomography (see the 'Assessment of injury' section). When we identified that $\mathrm{HCl}$ instillation involved the contralateral lung, the animals were euthanized and excluded from analysis (approximately 2\%). Anesthesia and paralysis were maintained throughout the experiment by infusion in the right carotid of Propofol $13 \mathrm{mg} / \mathrm{kg} / \mathrm{h}$ and Ketamine $5 \mathrm{mg} / \mathrm{kg} / \mathrm{h}$ and in the right jugular of Rocuronium bromide (Rocuronio, Fresenius Kabi Italia, Isola della Scala, Verona, Italy) $1.5 \mathrm{mg} / \mathrm{kg} / \mathrm{h}$ and Ringer acetate $1.8 \mathrm{ml} / \mathrm{h}$. A group of rats $(n=5)$, that received an instillation of $2.5 \mathrm{ml} / \mathrm{kg}$ of sterile saline $(\mathrm{NaCl} 0.9 \%)$ and underwent prolonged mechanical ventilation with same ventilation settings, was used as control group (CTRL). A group of healthy rats $(n=6)$ did not undergo any of the surgical interventions and was sacrificed (Healthy rats).

\section{Series 1 - early therapy with Ang-(1-7)}

Immediately after acid instillation, rats were randomized to receive intravenous treatment (left jugular vein) depending on the randomly assigned experimental group (infusion rate $200 \mu \mathrm{l} / \mathrm{kg} / \mathrm{h})$ : 
- Vehicle: rats treated with vehicle $(\mathrm{NaCl} 0.9 \%)$

- Ang-(1-7) low dose (ALD): rats treated with Ang-(1-7) at a dosage of $0.27 \mu \mathrm{g} / \mathrm{kg} / \mathrm{h}$

- Ang-(1-7) high dose (AHD): rats treated with Ang-(1-7) at a dosage of $60 \mu \mathrm{g} / \mathrm{kg} / \mathrm{h}$

\section{Series 2 - rescue therapy with Ang-(1-7)}

In this series, rats underwent high stretch ventilation and acid instillation as described above. Two hours after $\mathrm{HCl}$ instillation, animals were randomized to 'rescue' treatment with as follows:

- Vehicle: rats treated with vehicle $(\mathrm{NaCl} 0.9 \%)$

- Ang-(1-7) high dose: rats treated with Ang-(1-7) at a dosage of $100 \mu \mathrm{g} / \mathrm{kg} / \mathrm{h}$

In this series the total dose of Ang-(1-7) was the same as the AHD group in series 1.

\section{Hemodynamic monitoring}

In both series, invasive arterial, central venous, and airway pressures were monitored using pressure transducers, which were interfaced to a PowerLab (AD Instruments, Colorado Springs, CO, USA) signal transduction unit.

\section{Assessment of injury (after $\mathbf{5} \mathrm{h}$ of treatment in series $\mathbf{1}$ and $\mathbf{2}$ )}

Blood withdrawal: blood samples were collected at different time points: immediately before the treatment (start), after $3 \mathrm{~h}$ and at the end of the 5-h experiment (end), and they were collected from the right carotid artery to perform peripheral leukocyte (WBCs) counts.

Arterial blood gas analysis: at the same time points, gas exchange was assessed by measuring arterial pressure of oxygen $\left(\mathrm{PaO}_{2}\right)$, arterial pressure of carbon dioxide $\left(\mathrm{PaCO}_{2}\right), \mathrm{pH}$, and base excess $(\mathrm{BE})$ with i-STAT portable analyzer (Oxford Instruments S.M., Burke and Burke, Menfis Biomedica, Milan, Italy).

Computed tomography (CT) scan: animals underwent two CT scans (Skyscan 1176, Bruker, Brussels, Belgium). The first scan was performed immediately after the acid instillation in order to verify the extent of injury and the selective instillation of acid into the right lung, with these parameters: exposure $65 \mathrm{~ms}$, voltage $80 \mathrm{kV}$, current $300 \mu \mathrm{A}$, and resolution $35 \mu \mathrm{m}$ (scanning duration about $5 \mathrm{~min}$ ). At the end of the experiment, the second scan was performed in order to measure the amount of hypoaerated areas of parenchyma in the left and right lung separately. This scanning (taking about $20 \mathrm{~min}$ ) was gated on respiratory cycles.

Respiratory system compliance: respiratory system static compliance was measured every hour during mechanical ventilation by end-inspiratory occlusions and calculated according to standard formulas.

Broncho-alveolar lavage (BAL): rats were euthanized (via exsanguination), and BAL was performed in right and left lung separately. Total protein content and total and differential cell counts were analyzed, and BAL fluid were stored for inflammatory cytokines (interleukin-1 $\beta$ (IL-1 $\beta$ ), interleukin-6 (IL-6), keratinocyte-derived cytokine $(\mathrm{KC})$, macrophage inflammatory protein-1 $\alpha$ (MIP-1 $\alpha)$ ) dosage by luminex kit (Milliplex ${ }^{\circ}$ Map Kit, Millipore S.p.A., Vimodrone, Italy), according to manufacturer's instructions. 
Histology: histopathologic evaluations were performed in a blinded fashion by a pathologist (VC). Briefly, the lungs were excised, were fixed in $4 \%$ formaldehyde for $24 \mathrm{~h}$ (at a pressure of $20 \mathrm{cmH} 2 \mathrm{O}$ for the first $30 \mathrm{~min}$ ), and then paraffin embedded and sectioned. Transverse sections $(5 \mu \mathrm{m})$ were obtained by cutting the lungs from apex to base and then stained with hematoxylin and eosin (Sigma-Aldrich, St. Louis, MO, USA). Histopathologic examination was performed according to our previous study [25], evaluating the following six pathologic findings: alveolar serofibrinous exudate with hyaline membranes formation, alveolar hemorrhage, alveolar inflammatory cells, alveolar septa thickening, parenchymal necrosis, and fibrosis. Severity and extension of each pathologic finding were scored for severity as 0 (absent), 1 (mild), 2 (moderate), and 3 (marked) and for extension as 0 (absent), 1 ( $>0 \%$ and $\leq 25 \%), 2$ ( $>25 \%$ and $\leq 50 \%$ ), and $3(>50 \%)$. A mean score for each finding for each lung was derived and expressed as the product of extent and severity.

\section{Late ARDS study: unilateral acid aspiration model}

Rats were anesthetized with Ketamine $100 \mathrm{mg} / \mathrm{kg}$ and Xilazine $4 \mathrm{mg} / \mathrm{kg}$, orotracheally intubated and ventilated (Inspira ASV, Harvard Apparatus, Holliston, MA, USA) with the same parameters used above. $0.1 \mathrm{M} \mathrm{HCl}(2.5 \mathrm{ml} / \mathrm{kg})$ was instilled into the right bronchus through a PE10 catheter. The mechanical ventilation continued for $15 \mathrm{~min}$ and rats were maintained in the reverse-Trendelenburg position. Animals were extubated and kept in an oxygenated $\left(\mathrm{FiO}_{2}\right.$ 0.5) chamber until full awakening. Rats were housed three/cage for 2 weeks in Specific Pathogen Free conditions, until sacrifice. A group of healthy rats $(n=6)$ did not undergo any of the surgical interventions and was sacrificed (Healthy rats).

\section{Treatment protocol}

Administration of Ang-(1-7) or vehicle ( $\mathrm{NaCl} 0.9 \%)$ started 10 min after the $\mathrm{HCl}$ instillation through the use of Alzet mini-osmotic pumps (Model 2002, DURECT Corporation, Cupertino, CA, USA), which were implanted and tunneled subcutaneously, with a mean pumping rate of $0.44 \mu \mathrm{l} / \mathrm{h}$ for 2 weeks until the rats were sacrificed. Throughout the study period, dosages were maintained as specified above. In this part of the study, we studied only on the dose (300 $\mu \mathrm{g} / \mathrm{kg} /$ day) of Ang-(1-7), that demonstrated beneficial effects in the acute phase (see the 'Results' section). Ten rats were excluded from analysis ( $n=7$ vehicle, $n=3$ Ang1-7) because of an evident inflammatory reaction localized near the subcutaneous mini-osmotic pump, which casts some doubts on the actual drug delivery and represents an additional source of inflammation.

\section{Assessment of injury}

Blood oxygen saturation $\left(\mathrm{SpO}_{2}\right): 1$ week after the $\mathrm{HCl}$ instillation, the arterial hemoglobin saturation was measured through an animal oximeter pod (red and infrared light passed through pulsating blood in vascular tissue) placed on the hind leg (Animal Oximeter Pod, ML325, ADInstruments, Colorado Springs, CO, USA).

Respiratory system compliance: After 2 weeks of treatment in anesthetized rats, respiratory system compliance was measured through the construction of a PV curve: after a recruitment maneuver (to $30 \mathrm{cmH}_{2} \mathrm{O}$ for $10 \mathrm{~s}$ ), five steps of inspiratory volumes 
$(2.5 \mathrm{ml})$ were delivered, starting from functional residual capacity to a total volume of $12.5 \mathrm{ml}$. For each step, the plateau pressure was recorded in order to calculate the static compliance.

CT scan: rats underwent two micro-CT scans (eXplore Locus, GE Healthcare, Pewaukee, WI, USA): $24 \mathrm{~h}$ after injury and at the end of the experiment. The CT parameters were as follows: voltage $80 \mathrm{kV}$, current $450 \mu \mathrm{A}$, and resolution $93 \mu \mathrm{m}$. The scans were acquired over $10 \mathrm{~min}$. Images were analyzed to measure the amount of hypoaerated areas of parenchyma in the left and right lung separately.

Collagen content in pulmonary tissue: after animal's euthanasia, lungs were excised and stored at $-80^{\circ} \mathrm{C}$. The collagen content was measured indirectly with the $\mathrm{OH}$-proline assay. We used the conventional method, which entails lung tissue homogenization and hydrolysis with $6 \mathrm{~N} \mathrm{HCl}$ at $120^{\circ} \mathrm{C}$, chloramine T and Ehrlich's solution were added to samples for the $\mathrm{OH}$-proline oxidation and a colorimetric reaction. Absorbance was measured at $550 \mathrm{~nm}$.

\section{Exclusion criteria}

Animals were excluded from the protocol on fulfillment of two predefined criteria, namely: (1) evidence on CT of lung injury to the left lung following acid instillation (i.e., model failure); or (2) malfunctioning of the injection pumps (i.e., non-delivery of Ang(1-7)). In the case of animal death, this precluded further physiologic data collection, but animal survival data was included in the analysis.

\section{Statistical analysis}

All data presented in this report are expressed as mean \pm standard deviation. For the acute ARDS, study treatments with Ang-(1-7) at two doses and vehicle were compared by means of one way ANOVA analysis and followed by Tukey post hoc test. For the comparison between vehicle group and CTRL group, and between the two rescue treatment groups, $t$-test analysis was used. For the study of the late phase, angiotensin 1-7 was compared with vehicle by $t$-test analysis. A level of $p<0.05$ was considered as statistically significant.

\section{Results}

Acute ARDS study. Two-hit model

Series 1 - early therapy with Ang-(1-7)

Angiotensin-(1-7) effects on pulmonary pathophysiology We did not find any difference between groups in terms of hemodynamics and airway pressures during the experiment, as shown in Table 1.

Arterial oxygenation was similar in all groups immediately after acid instillation. At the end of the experiment, vehicle-treated rats showed a significant reduction in oxygenation compared to CTRL rats $(554 \pm 9 \mathrm{mmHg}, p=0.001)$. Ang-(1-7) treatment at both doses significantly attenuated the decrement in arterial oxygenation induced by acid instillation (Figure 1A) compared to vehicle treatment. Different treatments did not result in differences in terms of levels of carbon dioxide, $\mathrm{pH}$, and $\mathrm{BE}$.

As expected, lung compliance in vehicle group was significantly reduced if compared to CTRL rats $(0.44 \pm 0.03 ; p=0.014)$. All groups immediately after acid instillation showed similar respiratory system compliance, and Ang-(1-7) treatment seemed not to 
Table 1 Hemodynamics and airway pressure

\begin{tabular}{lccccc}
\hline Experimental groups $(\boldsymbol{n})$ & Part $(\mathbf{m m H g})$ & $\mathbf{C V P}(\mathbf{m m H g})$ & Paw $\left(\mathbf{c m H}_{\mathbf{2}} \mathbf{O}\right)$ & Ppeak $\left(\mathbf{c m H}_{\mathbf{2}} \mathbf{O}\right)$ & PEEP $\left(\mathbf{c m H}_{\mathbf{2}} \mathbf{O}\right)$ \\
\hline Vehicle (15) & $112 \pm 20$ & $3.2 \pm 0.9$ & $5.7 \pm 0.5$ & $19.7 \pm 2.0$ & $2.3 \pm 0.2$ \\
ALD (11) & $117 \pm 16$ & $3.0 \pm 0.8$ & $6.0 \pm 0.7$ & $21.5 \pm 3.5$ & $2.2 \pm 0.2$ \\
AHD (13) & $123 \pm 16$ & $3.4 \pm 0.8$ & $5.8 \pm 0.4$ & $19.7 \pm 1.5$ & $2.4 \pm 0.2$ \\
\hline
\end{tabular}

Part, arterial pressure; CVP, central venous pressure; Paw, mean airway pressure; Ppeak, peak of airway pressure; PEEP, positive end-expiratory pressure. Results are expressed as mean \pm SD.

affect the lung mechanical properties: all groups showed similar compliance values (Figure 2) measured at the end of experiment ( $5 \mathrm{~h}$ ).

Rats that received saline instillation instead of acid showed a significant lower alteration ( $p=0.019$ ) of permeability than vehicle group in the right lung: total protein content was $722 \pm 42 \mu \mathrm{g} / \mathrm{ml}$ in right and $692 \pm 29 \mu \mathrm{g} / \mathrm{ml}$ in left lung. Ang-(1-7) treatment did not modify the alteration of alveolar permeability, as the total protein content was very similar in all groups, as shown in Table 2 .

Angiotensin-(1-7) effects on inflammation As index of the systemic inflammation, peripheral white blood cell counts were performed: cellular counts were similar in all groups immediately after injury (vehicle: 8,271 $\pm 3,054$; ALD: 8,681 $\pm 2,919$; AHD: 9,085
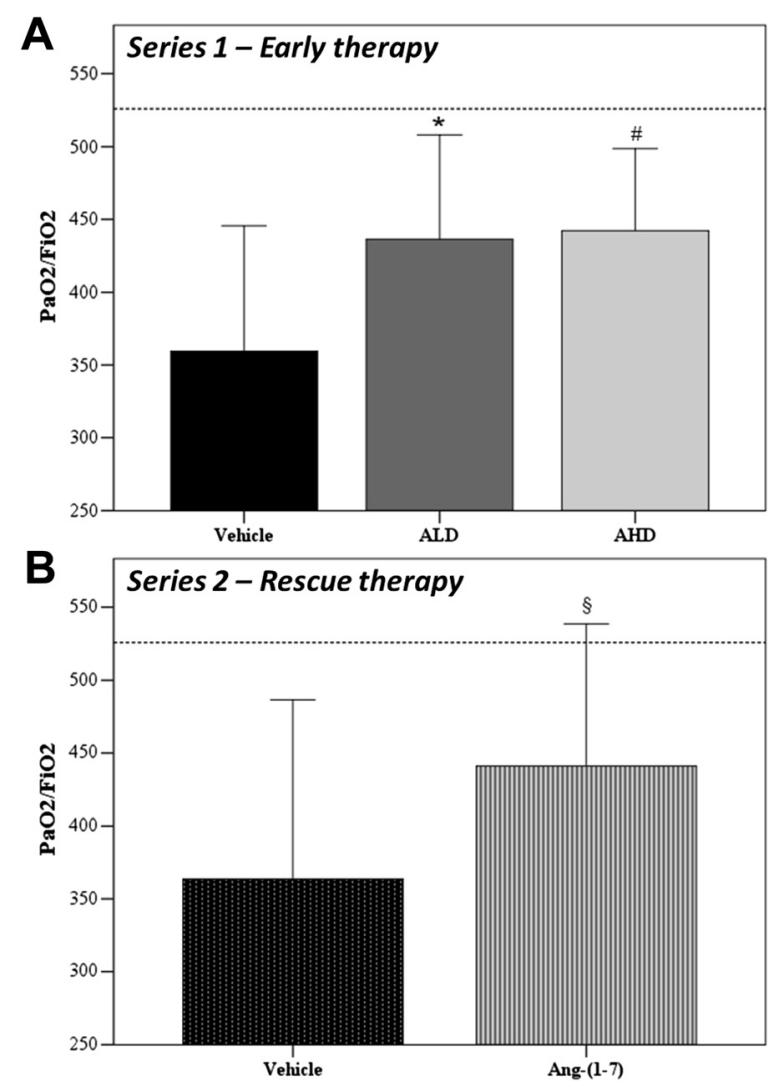

Figure 1 Partial pressure of oxygen and fraction of inspired oxygen ratio ( $\mathrm{PaO} 2 / \mathrm{FiO2})$ measured at the end of the protocol. (A) Series 1 - Early therapy: ANOVA effect of treatment at the end $p=0.007$; ${ }^{*} p=0.030$ and $\# p=0.013$ vs vehicle. Vehicle $n=14 ;$ ALD $n=11 ;$ AHD $n=13$. (B) Series 2 - Rescue therapy: $\S p=0.043$ vs vehicle. Vehicle $n=5$; Ang-(1-7) $n=5$. Healthy rats (dotted line). Results are expressed as mean \pm SD. 


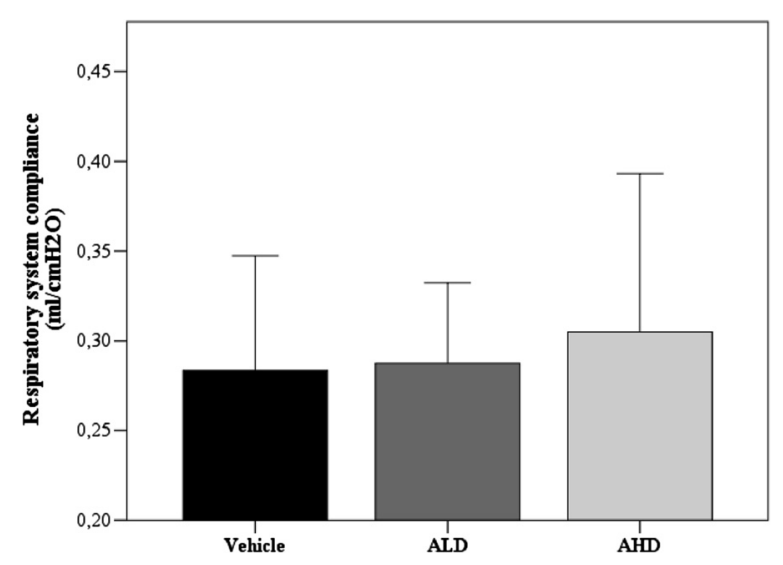

Figure 2 Final respiratory system compliance in vehicle and Ang-(1-7) (ANOVA $p=n . s$.$) treated groups.$ Vehicle $n=20 ; \mathrm{ALD} n=12 ; \mathrm{AHD} n=14$. Healthy rats $=0.65 \mathrm{ml} / \mathrm{cmH}_{2} \mathrm{O}$. Results are expressed as mean $\pm \mathrm{SD}$.

$\pm 2,479 / \mathrm{mm}^{3}$ ) and after $3 \mathrm{~h}$ (vehicle: 4,536 $\pm 2,211$; ALD: 3,071 $\pm 1,453$; AHD: 3,785 \pm $\left.1,622 / \mathrm{mm}^{3}\right)$, but after $5 \mathrm{~h}$ of treatment with Ang-(1-7) at both doses, the number was significantly reduced, compared to vehicle treatment (Figure 3). As a measure of the alveolar inflammatory response, we evaluated the alveolar cell recruitment and the cytokine levels. Ang-(1-7) treatment reduced the number of inflammatory cells recruited in BAL. In particular, the high dose treatment led to a lesser number of total cells in BAL in both lungs, whereas the low dose affected only the left lung (not directly injured by acid) (Figure 4A). Rats in CTRL group had significantly lower $(p=0.045)$ polymorphonuclear (PMN) count in BAL in the right lung (right lung: $15 \pm 5 / \mu \mathrm{l}$, left lung: $6 \pm 3 / \mu \mathrm{l}$ ) when compared to the vehicle treatment. While the number of PMN in BAL seemed to be not reduced in AHD group compared to the vehicle (Figure 4C).

We did not find any effect of Ang-(1-7) on cytokine BAL levels, as shown in Table 3.

Histology and imaging Major histopathological findings are summarized in Table 2 and Figure 5. A trend towards reduced alveolar inflammatory infiltrates, parenchymal necrosis and serofibrinous exudate, although not reaching statistical significance was noted

Table 2 BAL total protein concentration and histological analysis in vehicle and Ang-(1-7) treated groups

\begin{tabular}{lcccc}
\hline Alveolar permeability and histology & Lung & Vehicle & ALD & AHD \\
\hline Permeability: BAL total protein content & & & & \\
Protein content $(\mu \mathrm{g} / \mathrm{ml})$ & Right & $2,454 \pm 1,142$ & $2,600 \pm 844$ & $2,536 \pm 710$ \\
& Left & $1,108 \pm 668$ & $1,406 \pm 808$ & $1,213 \pm 610$ \\
Histological analysis & & & & \\
Alveolar serofibrinous exudate & Right & $1.4 \pm 0.5$ & $2.0 \pm 2.7$ & $1.2 \pm 0.9$ \\
& Left & $1.0 \pm 1.0$ & $1.0 \pm 1.0$ & $0.3 \pm 0.6$ \\
Alveolar hemorrhages & Right & $0.7 \pm 0.9$ & $0.7 \pm 1.1$ & $0.7 \pm 1.7$ \\
Alveolar inflammatory cells & Left & $0 \pm 0$ & $0 \pm 0$ & $0 \pm 0$ \\
Parenchymal necrosis & Right & $0.8 \pm 0.8$ & $0.4 \pm 1.2$ & $0.5 \pm 0.8$ \\
& Left & $0 \pm 0$ & $0 \pm 0$ & $0 \pm 0$ \\
\hline
\end{tabular}

Results are expressed as mean \pm SD. 


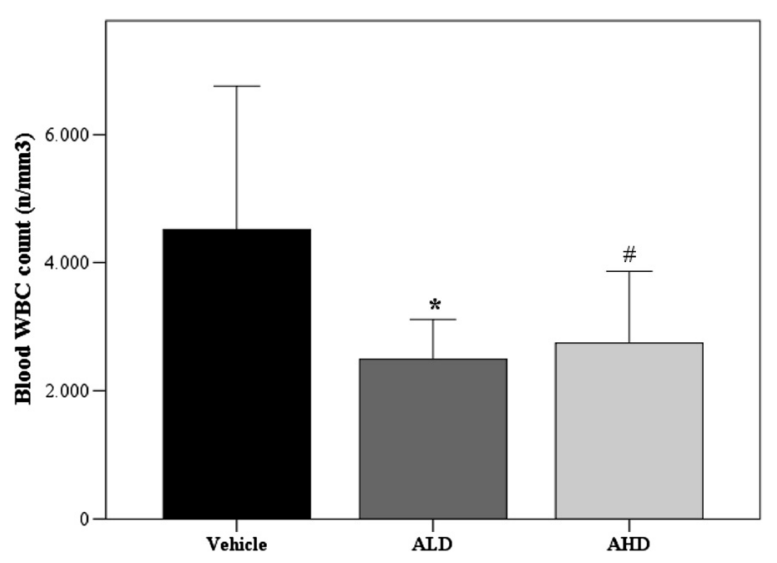

Figure 3 Peripheral white blood cells counts at the end of experiment (after $\mathbf{5} \mathbf{h}$ ). ANOVA, effect of treatment $p=0.004$. ${ }^{*} p=0.006$ and $\# p=0.025$ vs vehicle. Vehicle $n=15$; ALD $n=12$; AHD $n=10$. Results are expressed as mean $\pm \mathrm{SD}$.

in Ang-(1-7) treated group. The extent of alveolar hemorrhage was similar in all treatment groups.

No differences were found in terms of percentage of hypoaerated areas between groups, neither immediately after $\mathrm{HCl}$ instillation nor at the end of experiment (Figure 6).

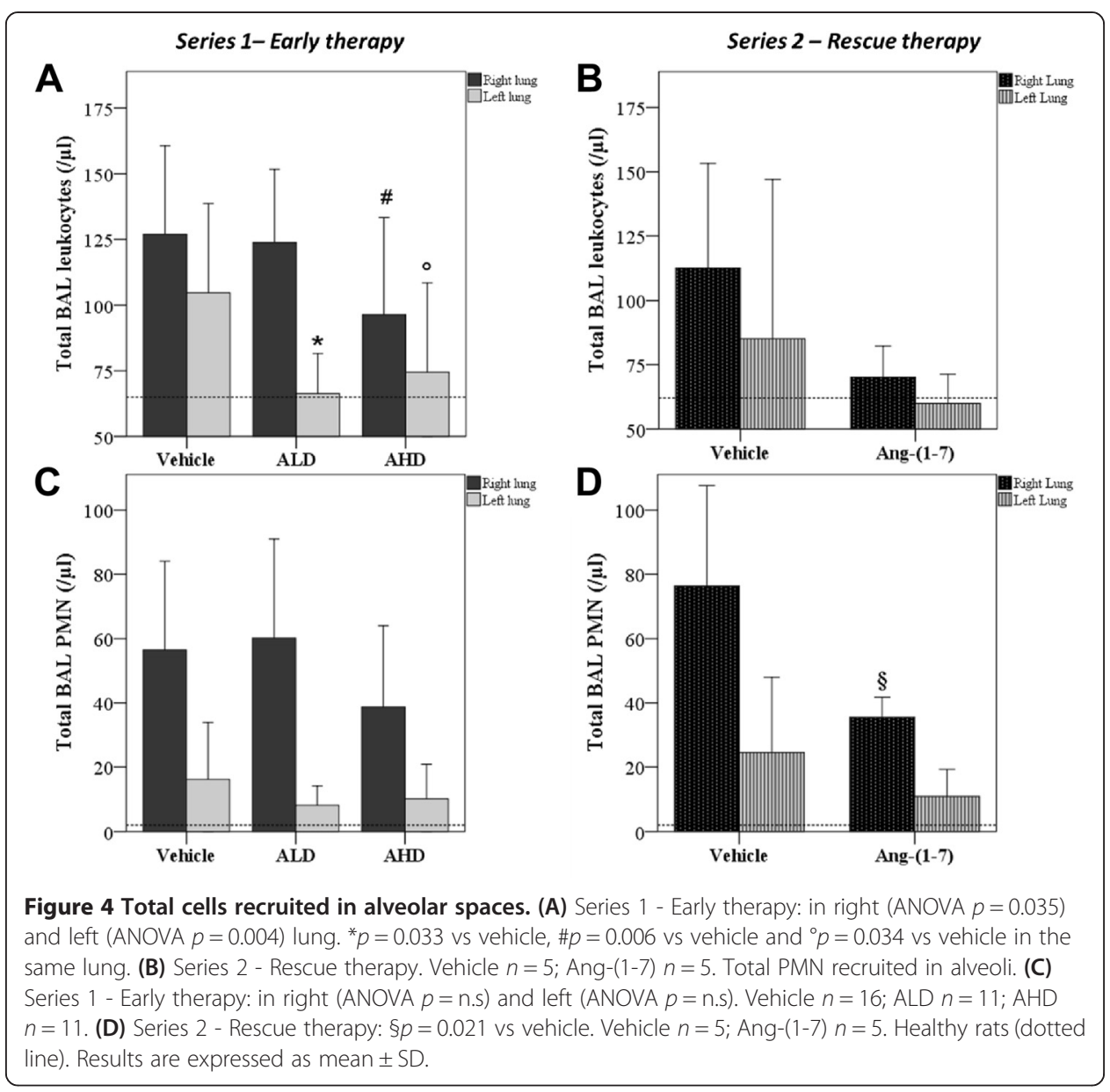


Table 3 BAL cytokines dosage $(\mathrm{pg} / \mathrm{ml})$ in vehicle and Ang-(1-7) treated groups

\begin{tabular}{|c|c|c|c|c|c|c|c|c|}
\hline \multirow{2}{*}{$\begin{array}{l}\text { Experimental } \\
\text { groups }(n)\end{array}$} & \multicolumn{2}{|c|}{ IL-1 $\beta(p g / m l)$} & \multicolumn{2}{|c|}{ IL-6 (pg/ml) } & \multicolumn{2}{|c|}{$\mathrm{KC}(\mathrm{pg} / \mathrm{ml})$} & \multicolumn{2}{|c|}{ MIP-1a (pg/ml) } \\
\hline & Right & Left & Right & Left & Right & Left & Right & Left \\
\hline Vehicle (14) & $68 \pm 32$ & $40 \pm 29$ & $3,423 \pm 1,460$ & $1,697 \pm 2,112$ & $2,133 \pm 608$ & $1,337 \pm 895$ & $45 \pm 35$ & $20 \pm 15$ \\
\hline ALD (10) & $91 \pm 47$ & $68 \pm 57$ & $3,771 \pm 1,647$ & $1,958 \pm 2,964$ & $3,003 \pm 1,257$ & $1,900 \pm 1,472$ & $67 \pm 39$ & $22 \pm 16$ \\
\hline AHD (9) & $83 \pm 23$ & $38 \pm 28$ & $4,465 \pm 1,972$ & $1,300 \pm 554$ & $2,809 \pm 1,198$ & $2,366 \pm 999$ & $54 \pm 22$ & $22 \pm 16$ \\
\hline Healthy rats (6) & $27 \pm 10$ & $15 \pm 6$ & $253 \pm 220$ & $357 \pm 78$ & $233 \pm 106$ & $104 \pm 43$ & $15 \pm 10$ & $10 \pm 8$ \\
\hline
\end{tabular}

Results are expressed as mean \pm SD. (ANOVA $p=$ n.s.).

Series 2 - rescue therapy with Ang-(1-7)

In series 2, Ang-(1-7) was effective in improving oxygenation and also if administrated as rescue treatment $2 \mathrm{~h}$ after the injury $(p=0.043)$, as shown in Figure $1 \mathrm{~B}$. Moreover, the rescue treatment with Ang-(1-7) induced a significant decrease $(p=0.021)$ in alveolar PMN in the right lung if compared to vehicle treatment, while no difference was detected in the left lung (Figure 4D). We also observed the effect of Ang-(1-7) on diuresis: the urine volume increased significantly if compared to vehicle group (vehicle: $2.9 \pm 0.6 \mathrm{ml} / 5 \mathrm{~h}$, Ang-(1-7): $7.9 \pm 4.2 \mathrm{ml} / 5 \mathrm{~h} ; p=0.030)$ ), which was not significant in series 1 (data not shown).

Late ARDS study. Unilateral acid aspiration model Angiotensin-(1-7) effects on lung fibrotic evolution

One week after acid instillation, blood oxygen saturation was significantly higher in Ang-(1-7) group compared to that in the vehicle group, as shown in Figure 7. Albeit the difference was minimal, it reinforces the finding of an improved oxygenation reported in the acute phase.

The lung mechanical properties measured at the end of experiment were not different between two groups: vehicle $0.65 \pm 0.14$ and Ang-(1-7) $0.62 \pm 0.06 \mathrm{ml} / \mathrm{cmH}_{2} \mathrm{O}$. Healthy rats showed a respiratory system compliance of $0.73 \pm 0.04 \mathrm{ml} / \mathrm{cmH}_{2} \mathrm{O}$.

At the end of experiment, right lungs from rats treated with angiotensin-(1-7) showed a significant reduction in collagen deposition, indirectly measured through $\mathrm{OH}$-proline assay (Figure 8).

\section{Discussion}

The RAS plays an important role in the pathogenesis of ARDS; in particular, it can be considered as an important element in the inflammatory response, since angiotensin II acts as a growth factor regulating cell growth and fibrosis [3]. The ACE2/Ang-(1-7) axis exerts protective effects in several pathological scenarios in different organs, by opposing the overactivation of ACE/Ang-II axis [19]. The aim of this study was to test the efficacy of angiotensin-(1-7) administration as treatment of ARDS in the two phases of the disease, the acute and the late in an experimental model of acid-induced lung injury.

To this end, we used our recently published two-hit model of acute lung injury [27] induced by unilateral acid instillation and prolonged injurious ventilation in these studies. A key feature of this model is the presence of a lung (the right one) subjected to a double insult (acid aspiration and injurious mechanical ventilation) and the other lung (left) that only receives injurious mechanical ventilation. This model is a valid model of 


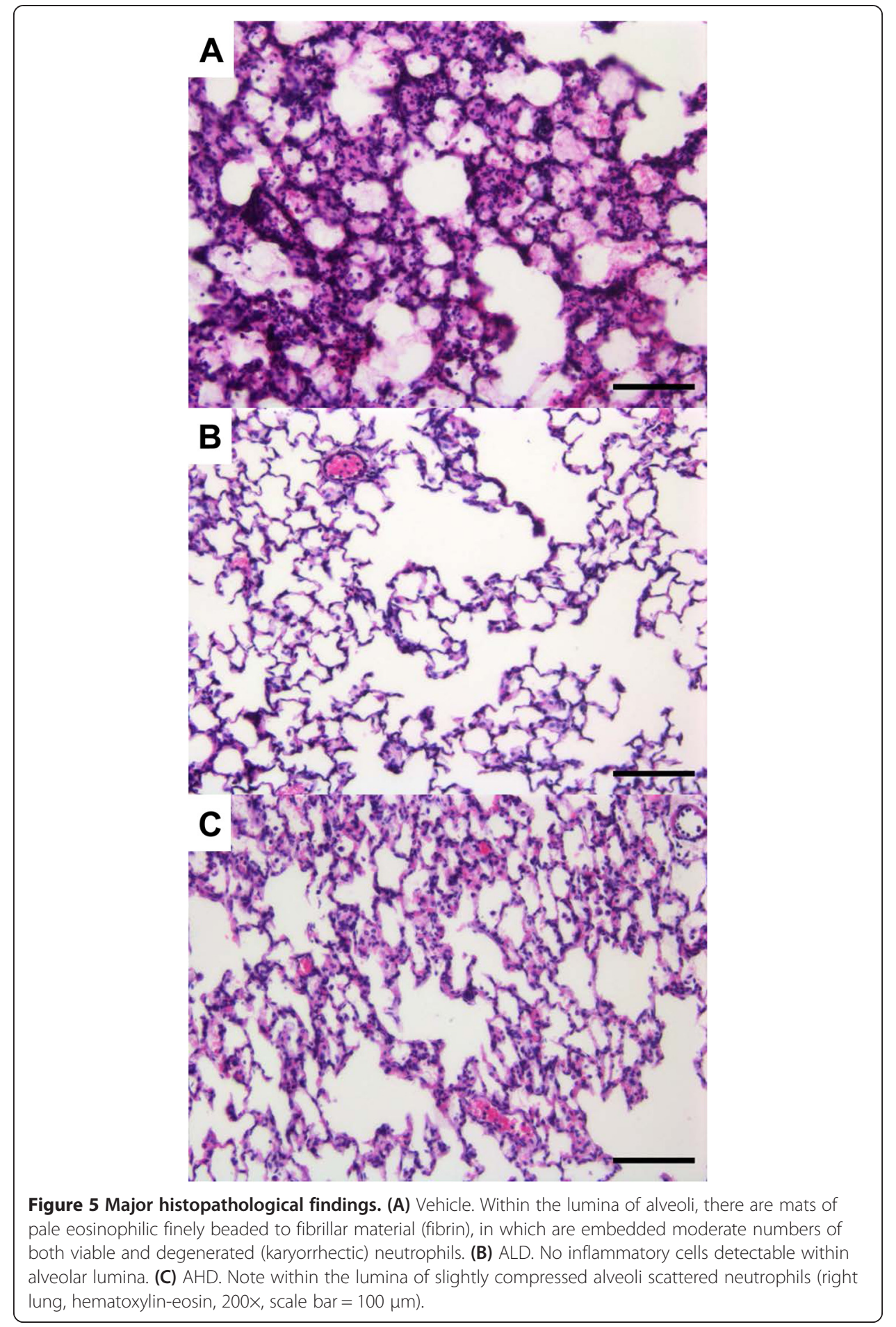

acute lung injury since it fulfilled the criteria laid out by Matute-Bello et al. [28]: histological evidence of tissue injury, alteration in the alveolar capillary barrier, presence of inflammatory response, and evidence of physiological dysfunction. It is known that high tidal volume ventilation causes VILI after acid instillation in rats [29]: however, to show that this model was more injurious than prolonged mechanical ventilation alone, rats treated with sterile saline instead of hydrochloric acid and mechanically ventilated for 

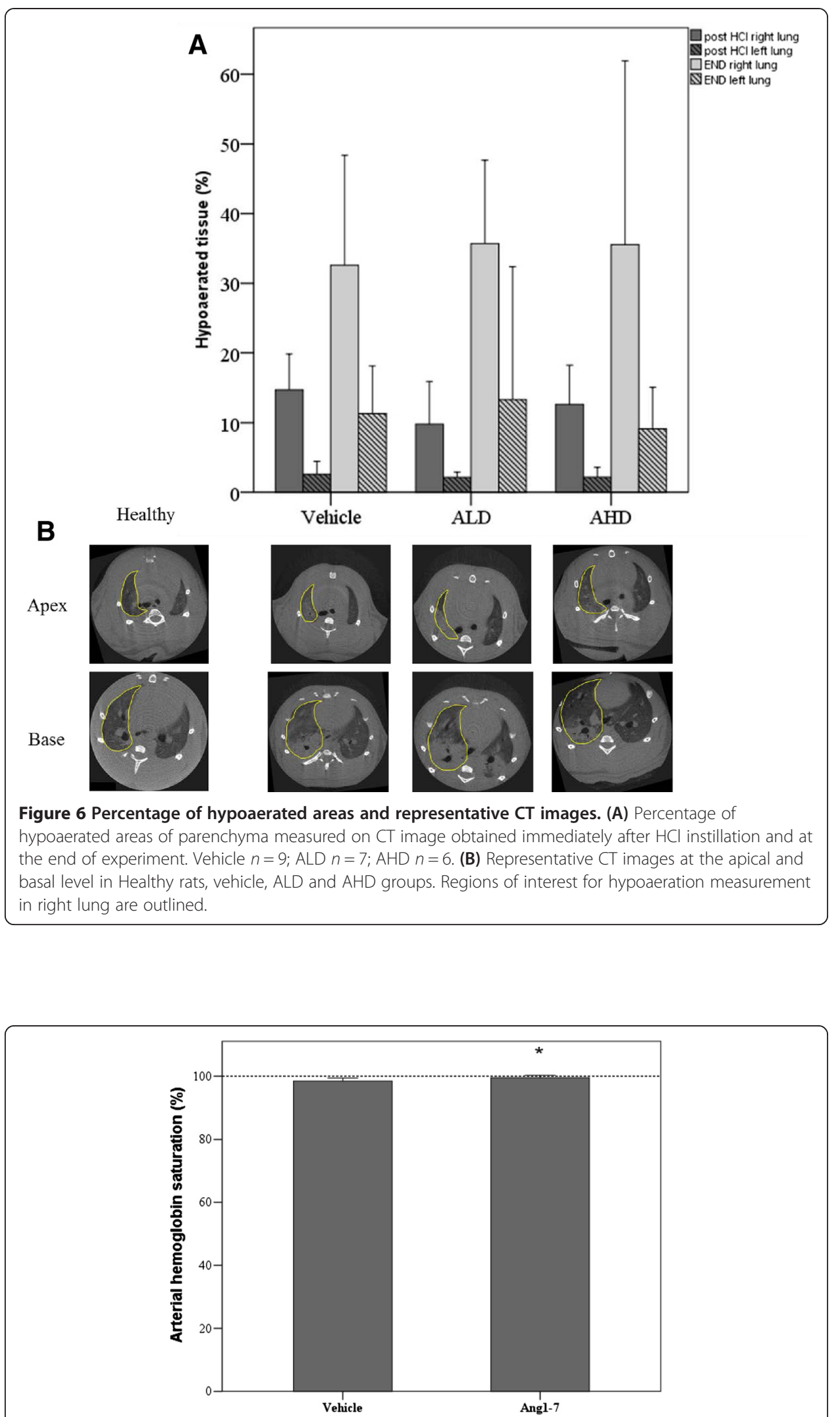

Figure 7 Arterial hemoglobin saturation in vehicle an Ang1-7 group. ${ }^{*} p=0.032$ vs Ang 1-7. Vehicle $n=7$; Ang-(1-7) $n=8$. Healthy rats (dotted line). Results are expressed as mean \pm SD. 


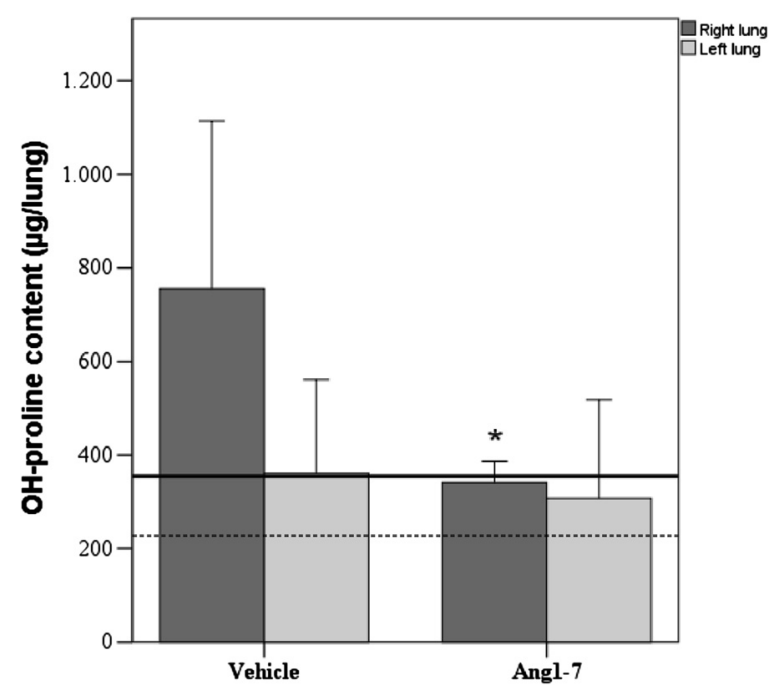

Figure $8 \mathrm{OH}$-Proline content in vehicle and Ang1-7 group. OH-Proline content in right and left lung shown separately, ${ }^{*} p=0.006$ vs Ang1-7 right lung. Vehicle $n=7$; Ang-(1-7) $n=8$. Healthy rats: right lung (solid black line) and left lung (dotted black line). Results are expressed as mean \pm SD.

$5 \mathrm{~h}$ were used as control. Our results demonstrated that the two-hit model showed a significant alteration of pulmonary function (gas exchange and respiratory system compliance), increase in PMN alveolar recruitment as index of inflammatory response, and alteration of alveolar capillary barrier. This model resembles to some extent the inhomogeneity of ARDS in the clinical setting. Indeed in the same subject, it's possible to study an area injured by acid instillation and mechanical ventilation (right lung) and at the same time a region injured by mechanical ventilation only (left lung).

Ang-(1-7) administration proved to be safe and well tolerated in our experimental setting: only a slight and transient (10 to $15 \mathrm{~min}$ ) decrease in systemic blood pressure was detected in the acute phase study, confirming the vasodilator effect of Ang-(1-7) which has been shown to be mediated through the production of endothelial nitric oxide [30]. We found no difference in survival in both ARDS studies: almost $80 \%$ of animals in all groups survived until the end of experiments.

The main findings obtained in the study are the beneficial effects of Ang-(1-7) on the oxygenation, inflammatory cells infiltrates, and fibrosis. The Ang-(1-7) treatment attenuated the decrease in gas exchange in rats subjected to acid instillation and $5 \mathrm{~h}$ of injurious mechanical ventilation: rats treated with Ang-(1-7) showed better partial pressure of oxygen compared to rats treated with vehicle only (an increase of $22 \%$ ). Interestingly, this finding was confirmed in the late ARDS model, 1 week after the acid instillation, as demonstrated by the measurement of blood oxygen saturation. It should be stressed that while this improvement (99.4\% vs $98.5 \%$ ) is certainly not clinically relevant, mostly because of the limited degree of hypoxia in this long-term model, at the same time, it supports the positive data obtained in the acute phase study. However, the lung function improvement did not seem to reflect on pulmonary mechanical properties. In fact, no improvement in respiratory system static compliance was detected in Ang-(1-7) higher dose group in acute phase study.

Inflammatory cell migration was significantly reduced in Ang-(1-7) groups: both numbers of white blood cells and total BAL cells (Figures 3 and 4A) are significantly 
lower than in the vehicle group, although only a slight reduction was evident in PMN count (Figure 4B). A reduced systemic spread of the local inflammatory stimulus could also explain the decreased peripheral white blood cells; at the same time, Ang(1-7) is known to have direct effects on erythropoiesis [31], although this mechanism is less likely due to the limited time of observation. Moreover, histological analysis showed a reduced although not statistically significant presence of alveolar inflammatory cells (Table 2). Overall, these results confirm Ang-(1-7)-mediated inhibition of leukocyte migration in different pathologies, such as acute renal injury [32], antigen-induced arthritis [17], and cardiomyopathy [21]. Moreover, a very recent study performed by Klein and coworkers [24] demonstrated how Ang-(1-7) protects from three experimental lung injury: oleic acid, acid aspiration, and mechanical ventilation. It clearly attenuated alveolo-capillary barrier failure, neutrophil influx into the lung, and histological evidence of lung injury. In contrast to our results on inflammatory cell lung influx, we failed to find any difference in BAL levels of different cytokines (IL-1 $\beta$, IL-6, KC, and MIP-1 $\alpha$ ). In fact, it seemed that Ang-(1-7) treatment did not affect cytokine production. These results are in line with those obtained by Arndt et al. in 2006 [33], that showed that the diminution in neutrophil recruitment in lung was not dependent on a decrease in neutrophil chemoattractants (i.e,. KC and MIP-2) in the setting of systemic ACE inhibition in lypopolysaccharide-induced lung injury in mice. A possible hypothesis that can be drawn to explain this finding is the involvement of nitric oxide (NO). Ang-(1-7) can induce the activation of endothelial NO synthase (eNOS) [34] and the bradykinin-mediated NO-release [35]. NO, besides its vasodilatory and anti-aggregant functions, inhibits neutrophil recruitment, by acting on neutrophil movement in vascular bed and on the neutrophil-endothelial interactions, via the suppression of adhesion molecules [36]. Although Klein et al. [24] found a significant protective effect of Ang-(1-7) on alveolo-capillary barrier, the total BAL protein content in our experimental setting was not different between the analyzed groups. One of the reasons for the lack of the effect on protein extravasation, in our study, could be related to the experimental model: the caustic action of acid direct on a limited area (right lung) and the following prolonged mechanical ventilation may cause such an intense fluid extravasation into the alveolar space that the 5-h time period could not be sufficient for the treatment to exert its entire effect.

The therapeutic potential of Ang-(1-7) treatment was underlined in a separate set of experiments (series 2), where 'rescue therapy' starting $2 \mathrm{~h}$ after $\mathrm{HCl}$ instillation demonstrated a significant improvement of arterial oxygenation and inflammatory response (in terms of PMN recruitment into alveoli). This is probably one of the major elements of novelty of this paper, when compared to the paper by Klein [24], in adjunct to the evaluation on the long-term development of fibrosis and the use of a two-hit model. Interestingly in this experiment, we found a role of Ang-(1-7) on diuresis: it seemed that a higher infusion rate of Ang-(1-7) $(100 \mu \mathrm{g} / \mathrm{kg} / \mathrm{h})$ induced an increase in urine volume if compared to vehicle treatment, confirming data in literature [37].

Another very interesting result is the beneficial effect of Ang-(1-7) treatment on the fibrotic evolution. In the second part of the study (late ARDS study), we tested the effects of the Ang-(1-7) only at the dose that had produced the better effects in the acute ARDS study. Two weeks after acid instillation, rats continuously treated with Ang-(1-7) had a significant reduction in collagen lung deposition (indirectly measured 
by $\mathrm{OH}$-proline assay), confirming recent studies performed by Chen et al. [38] and Meng et al. [39], that demonstrated protective effects of Ang-(1-7) treatment in murine LPS- or bleomycin-induced lung injury and lung fibrosis. The inhibitor effect of Ang-(1-7) on inflammatory cells recruitment seen in the acute phase study may be related to the reduction of fibrosis in the later phase. We have recently published [40] about the relationship between the inflammatory response and the fibrotic evolution, confirming previous data by Jones et al. [41]. Although Ang-(1-7) decreased pulmonary collagen deposition, it did not attenuate the decrement in respiratory system compliance in these animals. This might be explained with the fact that lung injury is restricted to a single lobe, and it is not so big to affect the whole respiratory system compliance.

The limitations of this study should also be acknowledged. First, we did not include a group of animals treated with blockers of Ang-II receptor (such as Losartan) or, vice-versa of Ang-II. Indeed, several studies showed beneficial effects of Losartan treatment in terms of attenuation of lung injury in the ARDS model [33,38,42-44]. Second, we did not demonstrate that the effects of Ang-(1-7) are mediated by Mas receptor, since we did not consider a group of animals treated with Mas receptor antagonist (A779). Ang-(1-7) mediates its lung effects through its own receptor and A779 exacerbates lung injury and collagen deposition [24,40,41].

\section{Conclusions}

In this study, angiotensin-(1-7) improved pulmonary function in terms of oxygenation and inflammatory cells recruitment in a two-hit model of ARDS, characterized by acid instillation and prolonged injurious ventilation. Ang-(1-7) was effective even when administration was delayed, emphasizing its true therapeutic potential. The more interesting finding, from a potential clinical perspective, is the persistence of an improved oxygenation and a reduced lung fibrosis, evaluated in the experimental model of acid aspiration alone. These results make Ang-(1-7) an exciting plausible therapy for ARDS and call for further research in this field.

The present study was partially supported by an unrestricted grant from Chiesi Farmaceutici S.p.A., Parma, Italy, and by the University of Milano-Bicocca, Monza, Italy. The funding sources had no involvement in study design or data collection, analysis, or interpretation or in the decisions concerning the drafting or the submission of this manuscript.

Authors' contributions

$\mathrm{GB}, \mathrm{SM}, \mathrm{RL}$, and AP planned the study and reviewed the analysis of the data. VZ and GB wrote the manuscript. VZ, RB, $F P, A G$, and MS conducted the study and analyzed the data. AD performed cytokines dosage. VC performed histological analysis. JGL contributed to data interpretation and manuscript draft. All authors read and approved the final manuscript.
}

Authors' information

A.D. is the recipient of a fellowship from the Italian Foundation for Cancer Research (FIRC).

Acknowledgements

We thank Rick Franklin (Tarix Pharmaceuticals LTD, Brookline, MA, USA) for his support in the study design and for the angiotensin fragment supply.

Author details

${ }^{1}$ Department of Health Sciences, University of Milano-Bicocca, Monza, Italy. ${ }^{2}$ Department of Emergency, San Gerardo Hospital, Monza, Italy. ${ }^{3}$ Mouse \& Animal Pathology Lab, Fondazione Filarete, Milan, Italy. ${ }^{4}$ Department of Cardiovascular Research, IRCCS - Istituto di Ricerche Farmacologiche Mario Negri, Milan, Italy. ${ }^{5}$ Department of Oncology, IRCCS Istituto di Ricerche Farmacologiche Mario Negri, Milan, Italy. ${ }^{6}$ Keenan Research Centre for Biomedical Science, St. Michael's Hospital, Toronto, ON, Canada. 7 Departments of Anesthesia and Physiology, University of Toronto, Toronto, ON, Canada. 
Received: 17 June 2014 Accepted: 7 February 2015

Published online: 27 February 2015

\section{References}

1. Frank AJ, Thompson BT (2010) Pharmacological treatments for acute respiratory distress syndrome. Curr Opin Crit Care 16:62-68

2. Dreyfuss D, Saumon G (1998) Ventilator-induced lung injury: lessons from experimental studies. Am J Respir Crit Care Med 157:294-323

3. Suzuki Y, Ruiz-Ortega M, Lorenzo O, Reperez M, Esteban V, Egido J (2003) Inflammation and angiotensin II. Int J Biochem Cell Biol 35:881-900

4. Marshall RP, Gohlke P, Chambers RC, Howell DC, Bottoms SE, Unger T, McAnulty RJ, Laurent GJ (2004) Angiotensin II and the fibroproliferative response to acute lung injury. Am J Physiol Lung Cell Mol Physiol 286:L156-L164

5. Simoes e Silva AC, Silveira KD, Ferreira AJ, Teixeira MM. ACE2, angiotensin-(1-7) and Mas receptor axis in inflammation and fibrosis (2013) Br J Pharmacol 169:477-492

6. Marshall RP, Webb S, Bellingan GJ, Montgomery HE, Chaudhari B, McAnulty RJ, Humphries SE, Hill MR, Laurent GJ (2002) Angiotensin converting enzyme insertion/deletion polymorphism is associated with susceptibility and outcome in acute respiratory distress syndrome. Am J Resp Crit Care Med 166:646-650

7. Cambien F, Alhenc-Gelas F, Herberth B, Andre JL, Rakotovao R, Gonzales MF, Allegrini J, Bloch C (1988) Familial resemblance of plasma angiotensin-converting enzyme level: the Nancy Study. Am J Hum Genet 43:774-780

8. Rigat B, Hubert C, Alhenc-Gelas F, Cambien F, Corvol P, Soubrier F (1990) An insertion/deletion polymorphism in the angiotensin I-converting enzyme gene accounting for half the variance of serum enzyme levels. J Clin Invest 86:1343-1346

9. Jerng JS, Yu CJ, Wang HC, Chen KY, Cheng SL, Yang PC (2006) Polymorphism of the angiotensin-converting enzyme gene affects the outcome of acute respiratory distress syndrome. Crit Care Med 34:1001-1006

10. Vickers C, Hales P, Kaushik V, Dick L, Gavin J, Tang J, Godbout K, Parsons T, Baronas E, Hsieh F, Acton S, Patane M, Nichols A, Tummino P (2002) Hydrolysis of biological peptides by human angiotensin-converting enzyme-related carboxypeptidase. J Biol Chem 277:14838-14843

11. Donoghue M, Hsieh F, Baronas E, Godbout K, Gosselin M, Stagliano N, Donovan M, Woolf B, Robison K, Jeyaseelan R, Breitbart RE, Acton S (2000) A novel angiotensin-converting enzyme-related carboxypeptidase (ACE2) converts angiotensin I to angiotensin 1-9. Circ Res 87:E1-E9

12. Bader M (2013) ACE2, angiotensin-(1-7), and Mas: the other side of the coin. Pflugers Arch 465:79-85

13. Zambelli V, Grassi A, Bellani G (2012) Role of the Renin-Angiotensin System in ARDS. In: Vincent JL (ed) Yearbook of intensive care and emergency medicine. Springer, Berlin

14. Benter IF, Diz DI, Ferrario CM (1993) Cardiovascular actions of angiotensin(1-7). Peptides 14:679-684

15. Tallant EA, Diz DI, Ferrario CM (1999) State-of-the-Art lecture. Antiproliferative actions of angiotensin-(1-7) in vascular smooth muscle. Hypertension 34:950-957

16. Grobe JL, Mecca AP, Lingis M, Shenoy V, Bolton TA, Machado JM, Speth RC, Raizada MK, Katovich MJ (2007) Prevention of angiotensin II-induced cardiac remodeling by angiotensin-(1-7). Am J Physiol Heart Circ Physiol 292:H736-H742

17. da Silveira KD, Coelho FM, Vieira AT, Sachs D, Barroso LC, Costa W, Bretas TL, Bader M, de Sousa LP, da Silva TA, dos Santos RA, Simões e Silva AC, Teixeira MM (2010) Anti-inflammatory effects of the activation of the angiotensin-(1-7) receptor, MAS, in experimental models of arthritis. J Immunol 185:5569-5576

18. Imai Y, Kuba K, Rao S, Huan Y, Guo F, Guan B, Yang P, Sarao R, Wada T, Leong-Poi H, Crackower MA, Fukamizu A, Hui CC, Hein L, Uhlig S, Slutsky AS, Jiang C, Penninger JM (2005) Angiotensin-converting enzyme 2 protects from severe acute lung failure. Nature 436:112-116

19. Passos-Silva DG, Verano-Braga T, Santos RA (2013) Angiotensin-(1-7): beyond the cardio-renal actions. Clin Sci (Lond) 124:443-456

20. Shah A, Oh YB, Lee SH, Lim JM, Kim SH (2012) Angiotensin-(1-7) attenuates hypertension in exercise-trained renal hypertensive rats. Am J Physiol Heart Circ Physiol 302:H2372-H2380

21. Oudit GY, Kassiri Z, Patel MP, Chappell M, Butany J, BackX PH, Tsushima RG, Scholey JW, Khokha R, Penninger JM (2007) Angiotensin II-mediated oxidative stress and inflammation mediate the age-dependent cardiomyopathy in ACE2 null mice. Cardiovasc Res 75:29-39

22. Lubel JS, Herath CB, Tchongue J, Grace J, Jia Z, Spencer K, Casley D, Crowley P, Sievert W, Burrell LM, Angus PW (2009) Angiotensin-(1-7), an alternative metabolite of the renin-angiotensin system, is up-regulated in human liver disease and has antifibrotic activity in the bile-duct-ligated rat. Clin Sci (Lond) 117:375-386

23. Shenoy V, Ferreira AJ, Qi Y, Fraga-Silva RA, Díez-Freire C, Dooies A, Jun JY, Sriramula S, Mariappan N, Pourang D, Venugopal CS, Francis J, Reudelhuber T, Santos RA, Patel JM, Raizada MK, Katovich MJ (2010) The angiotensin-converting enzyme 2/angiogenesis-(1-7)/Mas axis confers cardiopulmonary protection against lung fibrosis and pulmonary hypertension. Am J Respir Crit Care Med 182:1065-1072

24. Klein N, Gembardt F, Supé S, Kaestle SM, Nickles H, Erfinanda L, Lei X, Yin J, Wang L, Mertens M, Szaszi K, Walther T, Kuebler WM (2013) Angiotensin-(1-7) protects from experimental acute lung injury. Crit Care Med 41:e334-e343

25. Cabrera-Benitez NE, Laffey JG, Parotto M, Spieth PM, Villar J, Zhang H, Slutsky AS (2014) Mechanical ventilationassociated lung fibrosis in acute respiratory distress syndrome: a significant contributor to poor outcome. Anesthesiology [Epub ahead of print]

26. Amigoni M, Bellani G, Scanziani M, Masson S, Bertoli E, Radaelli E, Patroniti N, Di Lelio A, Pesenti A, Latini R (2008) Lung injury and recovery in a murine model of unilateral acid aspiration: functional, biochemical, and morphologic characterization. Anesthesiology 108:1037-1046

27. Amigoni M, Bellani G, Zambelli V, Scanziani M, Farina F, Fagnani L, Latini R, Fumagalli R, Pesenti A (2013) Unilatera acid aspiration augments the effects of ventilator lung injury also in the controlateral lung. Anesthesiology 119:642-651 
28. Matute-Bello G, Downey G, Moore BB, Groshong SD, Matthay MA, Slutsky AS, Kuebler WM, Acute Lung Injury in Animals Study Group (2011) An official American Thoracic Society workshop report: features and measurements of experimental acute lung injury in animals. Am J Respir Cell Mol Biol 44:725-738

29. Kuiper JW, Plötz FB, Groeneveld AJ, Haitsma JJ, Jothy S, Vaschetto R, Zhang H, Slutsky AS (2011) High tidal volume mechanical ventilation-induced lung injury in rats is greater after acid instillation than after sepsis-induced acute lung injury, but does not increase systemic inflammation: an experimental study. BMC Anesthesiol 11:26

30. Silva DM, Vianna HR, Cortes SF, Campagnole-Santos MJ, Santos RA, Lemos VS (2007) Evidence for a new angiotensin-(1-7) receptor subtype in the aorta of Sprague-Dawley rats. Peptides 28:702-707

31. Rodgers KE, Oliver J, diZerega GS (2006) Phase I/II dose escalation study of angiotensin 1-7 [A(1-7)] administered before and after chemotherapy in patients with newly diagnosed breast cancer. Cancer Chemoter Pharmacol 57:559-568

32. Barroso LC, Silveira KD, Lima CX, Borges V, Bader M, Rachid M, Santos RA, Souza DG, Simões E, Silva AC, Teixeira MM (2012) Renoprotective effects of AVE0991, a nonpeptide Mas receptor agonist, in experimental acute renal injury. Int J Hypertens 2012:808726

33. Arndt PG, Young SK, Poch KR, Nick JA, Falk S, Schrier RW, Worthen GS (2006) Systemic inhibition of the angiotensin-converting enzyme limits lipopolysaccharide-induced lung neutrophil recruitment through both bradykinin and angiotensin I-regulated pathways. J Immunol 177:7233-7241

34. Sampaio WO, Souza dos Santos RA, Faria-Silva R, da Mata Machado LT, Schiffrin EL, Touyz RM (2007) Angiotensin(1-7) through receptor Mas mediates endothelial nitric oxide synthase activation via Akt-dependent pathways. Hypertension 49:185-192

35. Peiró C, Vallejo S, Gembardt F, Azcutia V, Heringer-Walther S, Rodríguez-Mañas L, Schultheiss HP, Sánchez-Ferrer CF, Walther T (2007) Endothelial dysfunction through genetic deletion or inhibition of the G protein-coupled receptor Mas: a new target to improve endothelial function. J Hypertens 25:2421-2425

36. Roman A, Legallo R, McGahren ED (2004) Blocking of endogenous nitric oxide increases white blood cell accumulation in rat lung. J Pediatr Surg 39:48-52

37. Dilauro M, Burns KD (2009) Angiotensin-(1-7) and its effects in the kidney. ScientificWorldJournal 9:522-535

38. Chen Q, Yang Y, Huang Y, Pan C, Liu L, Qiu H (2013) Angiotensin-(1-7) attenuates lung fibrosis by way of Mas receptor in acute lung injury. J Surg Res 185:740-747

39. Meng Y, Yu CH, Li W, Luo W, Huang S, Wu PS, Cai SX, Li X (2014) Angiotensin-converting enzyme 2/Angiotensin(1-7)/Mas axis protects against lung fibrosis by inhibiting the MAPK/NF-kB pathway. Am J Respir Cell Mol Biol 50:723-736

40. Zambelli V, Di Grigoli G, Scanziani M, Valtorta S, Amigoni M, Belloli S, Messa C, Pesenti A, Fazio F, Bellani G, Moresco RM (2012) Time course of metabolic activity and cellular infiltration in a murine model of acid-induced lung injury. Intensive Care Med 38:694-701

41. Jones HA, Schofield J, Krausz T, Boobis A, Haslett C (1998) Pulmonary fibrosis correlates with duration of tissue neutrophil activation. Am J Respir Crit Care Med 158:620-628

42. Shen L, Mo H, Cai L, Kong T, Zheng W, Ye J, Qi J, Xiao Z (2009) Losartan prevents sepsis-induced acute lung injury and decreases activation of nuclear factor kappaB and mitogen-activated protein kinases. Shock 31:500-506

43. Raiden S, Nahmod K, Nahmod V, Semeniuk G, Pereira Y, Alvarez C, Giordano M, Geffner JR (2002) Nonpeptide antagonists of AT1 receptor for angiotensin II delay the onset of acute respiratory distress syndrome. J Pharmacol Exp Ther 303:45-51

44. Wösten-van Asperen RM, Lutter R, Specht PA, Moll GN, van Woensel JB, van der Loos CM, van Goor H, Kamilic J, Florquin S, Bos AP (2011) Acute respiratory distress syndrome leads to reduced ratio of ACE/ACE2 activities and is prevented by angiotensin-(1-7) or an angiotensin II receptor antagonist. J Pathol 225:618-627

\section{Submit your manuscript to a SpringerOpen ${ }^{\odot}$ journal and benefit from:}

- Convenient online submission

- Rigorous peer review

- Immediate publication on acceptance

- Open access: articles freely available online

- High visibility within the field

- Retaining the copyright to your article 